\title{
Neoadjuvant Chemotherapy in Triple Negative Breast Cancer: Correlation between Androgen Receptor Expression and Pathological Response
}

\author{
Amrallah A Mohammed ${ }^{1,2 *}$, Fifi Mostafa Elsayed ${ }^{3}$, Mohammed Algazar ${ }^{4}$, \\ Hayam E Rashed ${ }^{5}$, Abeer Hussien Anter ${ }^{6}$
}

\begin{abstract}
Background: There is growing evidence that the response to chemotherapy may be affected by Androgen Receptor (AR) expression suggesting that triple-negative breast cancers (TNBC) AR+ and quadruple negative breast cancer (QNBC) subtypes may have different diseases behavior. Methodology: We retrospectively estimated the predictive value of the AR expression in stage II and stage III TNBC patients treated with neoadjuvant chemotherapy (NAC) and correlated with the rate of pathological response (pCR). Results: Of 89 TNBC patients, 29 patients $(32.6 \%)$ were TNBC $\mathrm{AR}+$ and 60 patients (67.4) were QNBC. Most of the patients were less than 60 years old. Of note, approximately $62 \%$ in the QNBC group were less than 40 years old compared with $39 \%$ in the TNBC AR+ group. The Ki-67 expression was higher in the QNBC in comparison with TNBC AR+ being 86.7\% and 65.5\%, respectively. QNBC subgroup showed higher rates of pCR compared with TNBC; $60 \%$ and 24\%, respectively. Higher Ki-67 expression, higher grade, and lymph node involvement were statistically significantly correlated with the rate of pCR in the QNBC group $(p=0.02, p=0.04$, and $p=0.03$, respectively). In contrast, no significant association was observed between $p C R$ and clinical-pathological features in the TNBC AR+ group. Conclusion: Our results suggested that the AR expression in TNBC may be applied as a predictive marker for NAC. TNBC AR+ had a lower rate of pCR compared with QNBC, suggesting that this subtype may have a partial chemoresistance.
\end{abstract}

Keywords: Quadruple negative breast cancer- triple negative breast cancer- neoadjuvant chemotherapy

Asian Pac J Cancer Prev, 21 (2), 563-568

\section{Introduction}

Triple-negative breast cancer (TNBC) is a heterogeneous disease on the pathological, molecular, and clinical levels. It represents approximately $17 \%$ of all breast cancers (BCs) and have aggressive behavior compared to other molecular subtypes . QNBC is TNBC that lacks the expression of androgen receptor (AR), Estrogen receptor (ER), progesterone receptor (PR), and human epidermal growth factor receptor 2 (HER-2) and accounts for $63 \%-87 \%$ of TNBC with more aggressive behavior than the other molecular subtypes (Traina et al., 2018; Sutton et al., 2012; McNamara et al.,2013; Thike et al., 2014; Anand et al., 2017; Mina et al., 2017). There is increasing data that the growth of TNBC AR + is believed to be driven via signaling through the AR (Safarpour et al., 2014 and Collins et al., 2011).

Although TNBCs are heterogeneous diseases, they are treated in the same manner. Through Gene Expression
Profile (GEP), multiple subtypes had been placed with many clinical trials aimed to target different TNBC subtypes.

The role of androgen in normal breast tissue is well established and many data in the literature about the association with BC initiation and progression. However, its predictive and prognostic role is still in need of more clarification.

Neoadjuvant chemotherapy (NAC) is the standard of care for BC patients with locally advanced or even in with early stages (Mougalian et al., 2015).

It is established that the higher response rate for chemotherapy in TNBC did not translate into an improvement in survival outcomes. Nevertheless, many studies had suggested that achieving $\mathrm{pCR}$ is an effective surrogate marker for predicting long term survival outcomes (Telli et al., 2016).

The aim of the present study is to evaluate the predictive value of the AR expression in subset of patients

${ }^{1}$ Department of Medical Oncology, ${ }^{4}$ Department of General Surgery, ${ }^{5}$ Department of Pathology, Faculty of Medicine, Zagazig University, ${ }^{3}$ Department of Clinical Oncology and Nuclear Medicine, Faculty of Medicine, Suez Canal University, ${ }^{6}$ Department of Clinical Oncology and Nuclear Medicine, Mansoura University Egypt, ${ }^{2}$ Oncology Center, King Salman Armed Forces Hospital, TabukCity, Saudi Arabia.*For Correspondence: amrallaabdelmoneem@yahoo.com 
with TNBC treated with NAC and the correlation with the rate of $\mathrm{pCR}$.

\section{Materials and Methods}

\section{Patients and methods}

Eligibility criteria and sample size

The current multi-center retrospective study included 95 patients with stage II and stage III TNBC who diagnosed and treated at the Medical Oncology and General Surgical Departments, Faculty of Medicine Zagazig University, Egypt, Clinical Oncology and Nuclear Medicine department, Mansoura University, Egypt, and the Oncology Center in King Abdullah Medical City, Saudi Arabia, between the period from March 2012 and December 2015.

Patients with good performance status (ECOG 0-2) and measurable diseases received 6-8 cycles of NAC whereas those with prior chemotherapy or having insufficient cardiac, hepatic, renal and/or bone marrow functions were excluded.

\section{Collection of the data and ethical aspect}

The data were collected through medical chart review. This is a retrospective chart review study with no informed consent was obtained. The data sheet for statistics was not containing patients' identifiers and was connected to the data collection forms using a serial code number. The institutional review board (IRB) approved the study.

Diagnosis, immunohistochemistry technique and staging system

All cases were pathologically diagnosed after true cut needle biopsy. The cut-off value for AR, ER and PR positivity was $\geq 1 \%$, and for Ki-67 was $\geq 14 \%$. HER 2 was assessed by IHC and/or fluorescence in situ hybridization (FISH). HER2 positive was scored as IHC $3+$ or FISH (+).

QNBC was defined as any tumors with AR (-) ER (-), PR (-) and HER-2 (-) irrespective to the expression of basal cytokeratin and epidermal growth factor receptor (EGFR).

The work-up was based on NCCN guideline (2012) and staged according to the Joint Committee on Cancer (AJCC), 7th edition (2010) staging system).

\section{Pathological response evaluation}

Complete pathological response ( $\mathrm{pCR}$ ) is defined as no invasive residual in the breast or nodes. Treatment regimen

The chemotherapy protocol was institutionally based. One day before each cycle, routine laboratory investigations in the form of complete blood count, liver and kidney functions were requested. After completion of the protocol, the patients underwent breast conservation surgery or modified radical mastectomy (MRM).

\section{Statistical analysis}

The descriptive statistics used for patients' characteristics. The Chi-square test used to define the relationship between expressions of different markers $p$ values below 0.05 was considered significant.

\section{Results}

During the study period, nighty five patients diagnosed stage II-III TNBC received NAC. 6 patients were excluded due to insufficient data. Based on AR expression, 60 patients $(67.4 \%)$ were AR- (QNBC), while 29 patients (32.6\%) were TNBC AR+. Photomicrographs of TNBC AR+ and QNBC showed in Figure 1 (A and B) respectively. Figure 2 illustrated the treatment flow chart.

Table 1. Clinical and Pathological Features of TNBC $\mathrm{AR}+$ and TNBC AR

\begin{tabular}{|c|c|c|c|c|c|}
\hline \multirow[t]{2}{*}{ Variables } & \multicolumn{2}{|c|}{$\begin{array}{c}\text { TNBC AR+ } \\
(\mathrm{No}=29)\end{array}$} & \multicolumn{2}{|c|}{$\begin{array}{c}\text { TNBC AR- } \\
(\mathrm{No}=60)\end{array}$} & \multirow[t]{2}{*}{$\mathrm{P}$ value } \\
\hline & No & $\%$ & No & $\%$ & \\
\hline \multicolumn{6}{|l|}{ Age (years) } \\
\hline$\leq 40$ & 11 & 37.9 & 37 & 61.7 & \multirow[t]{3}{*}{$.003 *$} \\
\hline$>40-60$ & 14 & 48.3 & 22 & 36.7 & \\
\hline$\geq 60$ & 4 & 13.8 & 1 & 1.6 & \\
\hline \multicolumn{6}{|l|}{ Menopause status } \\
\hline Premenopausal & 16 & 55.2 & 47 & 78.3 & \multirow[t]{2}{*}{0.1} \\
\hline postmenopausal & 13 & 44.8 & 13 & 21.7 & \\
\hline \multicolumn{6}{|l|}{ Pathology } \\
\hline IDC & 25 & 86.2 & 50 & 83.3 & \multirow[t]{2}{*}{0.7} \\
\hline Non-IDC & 4 & 13.8 & 10 & 16.7 & \\
\hline \multicolumn{6}{|l|}{ Grade } \\
\hline I & 0 & 0.0 & 0 & 0.0 & \multirow[t]{3}{*}{0.9} \\
\hline II & 7 & 24.1 & 9 & 15.0 & \\
\hline III & 22 & 75.9 & 51 & 85.0 & \\
\hline \multicolumn{6}{|l|}{ LVI } \\
\hline Yes & 17 & 58.6 & 24 & 40.0 & \multirow[t]{2}{*}{0.6} \\
\hline No & 12 & 41.4 & 36 & 60.0 & \\
\hline \multicolumn{6}{|l|}{$\mathrm{T}$} \\
\hline $\mathrm{T} 1$ & 3 & 10.3 & 9 & 15.0 & \multirow{4}{*}{0.8} \\
\hline $\mathrm{T} 2$ & 12 & 41.4 & 21 & 35.0 & \\
\hline $\mathrm{T} 3$ & 11 & 37.9 & 23 & 38.3 & \\
\hline $\mathrm{T} 4$ & 3 & 10.3 & 7 & 11.7 & \\
\hline \multicolumn{6}{|l|}{$\mathrm{LN}$} \\
\hline No & 0 & 0.0 & 5 & 8.3 & \multirow{4}{*}{0.9} \\
\hline N1 & 13 & 44.8 & 22 & 36.7 & \\
\hline $\mathrm{N} 2$ & 14 & 48.3 & 24 & 40.0 & \\
\hline N3 & 2 & 6.9 & 9 & 15.0 & \\
\hline \multicolumn{6}{|l|}{ Ki-67 } \\
\hline Low & 10 & 34.5 & 8 & 13.3 & \multirow[t]{2}{*}{$.02 *$} \\
\hline High & 19 & 65.5 & 52 & 86.7 & \\
\hline \multicolumn{6}{|c|}{ Pathological response } \\
\hline $\mathrm{pCR}$ & 7 & 24.1 & 36 & 60.0 & \multirow{4}{*}{$0.01 *$} \\
\hline Non pCR & & & & & \\
\hline $\mathrm{pPR}$ & 16 & 55.2 & 20 & 33.3 & \\
\hline $\mathrm{pSD}$ & 6 & 20.7 & 4 & 6.7 & \\
\hline
\end{tabular}

$\overline{\mathrm{TNBC}}$, triple negative breast cancer; $\mathrm{AR}+$, androgen receptor positive; AR-, androgen receptor negative; IDC, invasive duct carcinoma; LVI, lympho-vascular space invasion; T, tumor size; LN, clinical lymph node status; pCR, pathological complete response; pPR, pathological partial response; pSD, pathological stable response; *P value $<0.05$ significant. 
Table 2. The Correlation between the pCR and Different Clinical-Pathological Features

\begin{tabular}{|c|c|c|c|c|c|c|c|c|c|c|}
\hline \multirow{4}{*}{ Variables } & \multicolumn{5}{|c|}{$\begin{array}{c}\text { TNBC AR }+ \\
\mathrm{No}=29\end{array}$} & \multicolumn{5}{|c|}{$\begin{array}{c}\text { TNBC AR- } \\
\qquad \mathrm{No}=60\end{array}$} \\
\hline & \multirow{2}{*}{\multicolumn{2}{|c|}{$\begin{array}{c}\mathrm{pCR} \\
\mathrm{No}=7\end{array}$}} & \multirow{2}{*}{\multicolumn{2}{|c|}{$\begin{array}{c}\text { Non pCR } \\
\mathrm{No}=22\end{array}$}} & \multirow[t]{3}{*}{$P$ value } & \multicolumn{2}{|c|}{$\mathrm{pCR}$} & \multicolumn{2}{|c|}{ Non pCR } & \multirow[t]{3}{*}{$\mathrm{P}$ value } \\
\hline & & & & & & \multicolumn{2}{|c|}{$\mathrm{No}=36$} & \multicolumn{2}{|c|}{$\mathrm{No}=24$} & \\
\hline & No & $\%$ & No & $\%$ & & No & $\%$ & No & $\%$ & \\
\hline \multicolumn{11}{|l|}{ Age (years) } \\
\hline$\leq 40$ & 3 & 42.8 & 8 & 36.4 & & 23 & 63.9 & 14 & 58.3 & \\
\hline$>40-60$ & 2 & 28.6 & 12 & 54.5 & 0.7 & 12 & 33.3 & 10 & 41.7 & 0.8 \\
\hline$\geq 60$ & 2 & 28.6 & 2 & 9.1 & & 1 & 2.8 & 0 & 0.0 & \\
\hline \multicolumn{11}{|l|}{ Menopause status } \\
\hline Premenopausal & 5 & 71.4 & 11 & 50.0 & 0.7 & 22 & 61.1 & 15 & 62.5 & 0.9 \\
\hline postmenopausal & 2 & 28.6 & 11 & 50.5 & & 14 & 38.9 & 9 & 37.5 & \\
\hline \multicolumn{11}{|l|}{ Pathology } \\
\hline IDC & 7 & 100.0 & 18 & 81.8 & 0.6 & 32 & 88.9 & 18 & 75.0 & 0.2 \\
\hline Non-IDC & 0 & 0.0 & 4 & 18.2 & & 4 & 11.1 & 6 & 25.0 & \\
\hline \multicolumn{11}{|l|}{ Grade } \\
\hline I & 0 & 0.0 & 0 & 0.0 & 0.2 & 0 & 0.0 & 0 & 0.0 & $0.04 *$ \\
\hline II & 2 & 28.6 & 5 & 22.7 & & 7 & 19.4 & 10 & 41.7 & \\
\hline III & 5 & 71.4 & 17 & 77.3 & & 29 & 80.6 & 14 & 58.3 & \\
\hline \multicolumn{11}{|l|}{ LVI } \\
\hline Yes & 1 & 14.3 & 16 & 72.7 & 0.3 & 14 & 33.3 & 12 & 50.0 & 0.2 \\
\hline No & 6 & 85.7 & 6 & 27.3 & & 24 & 66.7 & 12 & 50.0 & \\
\hline \multicolumn{11}{|l|}{$\mathrm{T}$} \\
\hline $\mathrm{T} 1$ & 1 & 14.3 & 2 & 9.1 & & 5 & 13.9 & 5 & 20.8 & \\
\hline $\mathrm{T} 2$ & 3 & 42.8 & 9 & 40.9 & 0.7 & 16 & 44.4 & 12 & 50.0 & 0.3 \\
\hline $\mathrm{T} 3$ & 2 & 28.6 & 9 & 40.9 & & 13 & 36.1 & 4 & 16.7 & \\
\hline $\mathrm{T} 4$ & 1 & 14.3 & 2 & 9.1 & & 2 & 5.6 & 3 & 12.5 & \\
\hline \multicolumn{11}{|l|}{ LN } \\
\hline N0 & 0 & 0.0 & 0 & 0.0 & & 4 & 11.1 & 1 & 4.2 & \\
\hline N1 & 5 & 71.4 & 8 & 36.4 & 0.4 & 16 & 44.4 & 6 & 25.0 & $0.03 *$ \\
\hline N2 & 2 & 28.6 & 12 & 54.5 & & 9 & 25.0 & 15 & 62.5 & \\
\hline N3 & 0 & 0.0 & 2 & 9.1 & & 7 & 19.4 & 2 & 8.3 & \\
\hline \multicolumn{11}{|l|}{ Ki67 } \\
\hline Low & 5 & 71.4 & 5 & 22.7 & 0.5 & 2 & 5.6 & 6 & 25.0 & $0.03 *$ \\
\hline High & 2 & 28.6 & 17 & 77.3 & & 34 & 94.4 & 18 & 75.0 & \\
\hline
\end{tabular}

TNBC, triple negative breast cancer; AR+, androgen receptor positive; AR-, androgen receptor negative; IDC, invasive duct carcinoma; LVI, lymphovascular space invasion; $\mathrm{T}$, tumor size; $\mathrm{N}$, clinical lymph node status. ${ }^{*} \mathrm{P}$ value $<0.05$ significant.

Most of the patients were less than 60 years old. Of note, approximately $62 \%$ were less than 40 years old in QNBC group compared with $39 \%$ in the TNBC AR+ group.

The premenopausal state represented the main bulk of our patients, being $78.3 \%$ and $55.2 \%$ of QNBC and TNBC AR+ group, respectively.

Regarding the histopathological features, there was no grade I in the studied groups. However, grade III was more common in the QNBC group, 85\% versus $75.9 \%$ in the TNBC AR+.

The majority of patients in the two groups had tumor size ranged from $2 \mathrm{~cm}$ to $5 \mathrm{~cm}$ (T3 \&T4); $73 \%$ and 79\%, a clinical lymph node involvement in 91.7 and $100 \%$ for $\mathrm{QNBC}$ and TNBC AR+ respectively. By using the cutoff value $14 \%$ or more, the Ki-67 expression, the proliferative marker was higher in QNBC group compared with TNBC $\mathrm{AR}+$ group $(86.7 \%$ and $65.5 \%$, respectively). Moreover, $60 \%$ of TNBC AR-patients achieved pCR compared with $24 \%$ in TNBC AR+. Clinical-pathological features and pathological response of QNBC and TNBC AR+ illustrated in Table 1.

Higher Ki-67 expression, higher grade, and lymph node involvement were statistically significantly correlated with the rate of $\mathrm{pCR}$ in the QNBC group ( $\mathrm{p}=0.02, \mathrm{p}=0.04$, and $\mathrm{p}=0.03$, respectively). While no significant association was observed in the TNBC AR+ group. Table 2 illustrates the correlation between the $\mathrm{pCR}$ and different clinicalpathological features.

Among the univariate analysis, TNBC AR-, high 


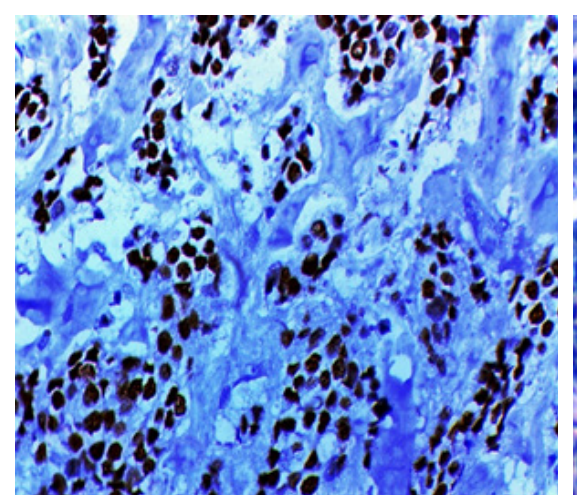

(A). TNBC AR+

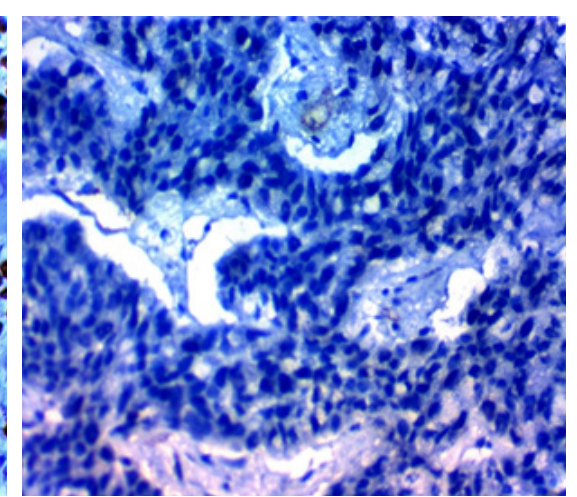

(B). TNBC AR- (QNBC)

Figure 1. Photomicrographs of Triple Negative Breast Cancers with androgen Receptor Positive (A) and androgen receptor negative (B)Immunohistochemistry X 400 (for A and B). TNBC, triple negative breast cancer; AR+, androgen receptor positive; AR-, androgen receptor negative; QNBC, quadruple negative breast cancer.

Ki-67 expression, IDC pathology type, and presence of LVI were associated with pCR $(\mathrm{OR}=7.960,95 \% \mathrm{CI}$, $\mathrm{p}=0.001 ; \mathrm{OR}=9.212,95 \% \mathrm{CI}, \mathrm{p}=0.001 ; \mathrm{OR}=0.244,95 \%$ $\mathrm{CI}, \mathrm{p}=0.007 ; \mathrm{OR}=0.573,95 \% \mathrm{CI}, \mathrm{p}=0.06$ ) respectively. Table 3 illustrates a univariate analysis for predictors the pathological response.

\section{Discussion}

The elegant progress of target therapies in $\mathrm{HR}+/ \mathrm{Her}-2+$ $\mathrm{BC}$ forced the investigators to recognize target therapies in TNBC. The introduction of AR evaluation in these subgroups of patients is really a huge step forward as it may help to determine the disease behavior (Biswas et al., 2017).

In our results, we observed that $67.4 \%$ of TNBC are QNBC. Most of the patients (61.7\%) in QNBC were at the age of 40 years or younger compared with $37.9 \%$ in the TNBC AR+ group $(\mathrm{p}=0.003)$. This translated into the distribution of the menopausal status, as 78\% in QNBC group was a premenopausal while, it was $52 \%$ in the TNBC AR+ group.

Generally, high Ki-67 expression was significantly associated with the TNBC subtype (Ilie et al., 2018 and Elnemr et al., 2016). In the current study, TNBC AR+ has lower proliferation rates and lower histological grade compared with QNBC. This approximated to the range of previously published studies (Traina et al., 2018; Sutton et al., 2012; McNamara et al., 2013; Thike et al., 2014; Anand et al., 2017; Mina et al., 2017).

In a meta-analysis conducted on 2,826 patients with TNBC from 13 trials. Wang et al., (2016) reported that TNBC AR+ was detected in $24.4 \%$ of the whole TNBC group and was associated with postmenopausal status,

Table 3. Univariate Analysis for Predictors the Pathological Response

\begin{tabular}{|c|c|c|c|c|c|c|c|}
\hline \multirow[b]{3}{*}{ Variate } & \multicolumn{3}{|c|}{$\begin{array}{l}\text { Pathological complete response } \\
\text { pCR }\end{array}$} & \multicolumn{4}{|c|}{$\begin{array}{l}\text { Non-pathological complete response } \\
\text { Non-pCR }\end{array}$} \\
\hline & \multirow[t]{2}{*}{ OR } & \multicolumn{2}{|c|}{$95 \% \mathrm{CI}$} & \multirow[t]{2}{*}{ OR } & \multicolumn{2}{|c|}{$95 \% \mathrm{CI}$} & \multirow[t]{2}{*}{$\mathrm{P}$ value } \\
\hline & & Lower & Upper & & Lower & Upper & \\
\hline Age & 0.56 & 0.241 & 1.303 & 1.768 & 0.767 & 4.156 & 0.1 \\
\hline \multicolumn{8}{|l|}{ Menopause } \\
\hline Pre vs post & 0.688 & 0.311 & 1.52 & 1.454 & 0.658 & 3.214 & 0.3 \\
\hline \multicolumn{8}{|l|}{ Pathology } \\
\hline IDC vs non IDC & 0.224 & 0.075 & 0.665 & 4.469 & 1.503 & 13.287 & $0.007 *$ \\
\hline \multicolumn{8}{|l|}{ Grade } \\
\hline II vs III & 1.444 & 0.602 & 3.465 & 0.692 & 0.289 & 1.661 & 0.4 \\
\hline \multicolumn{8}{|l|}{ LVI } \\
\hline Yes or No & 0.573 & 0.215 & 1.039 & 2.114 & 0.963 & 4.641 & $0.06^{*}$ \\
\hline Tumor size & 1.174 & 0.523 & 5.823 & 0.852 & 0.269 & 2.694 & 0.7 \\
\hline $\mathrm{LN}$ & 0.706 & 0.147 & 3.395 & 1.417 & 0.295 & 6.814 & 0.6 \\
\hline \multicolumn{8}{|l|}{ Ki 67} \\
\hline Low vs high & 9.212 & 2.521 & 33.66 & 0.109 & 0.03 & 0.397 & $0.001 *$ \\
\hline \multicolumn{8}{|l|}{ TNBC } \\
\hline AR+ vs AR- & 7.96 & 2.492 & 25.427 & 0.126 & 0.039 & 0.401 & $0.001 *$ \\
\hline
\end{tabular}

IDC, invasive duct carcinoma; LVI, lymphovascular space invasion; T, tumor size; LN; lymph node status; TNBC, triple negative breast cancer; $\mathrm{AR}+$, androgen receptor positive; AR-, androgen receptor negative. *P value $<0.05$ significant. 
low tumor grade and high risk of nodal involvement. Consistently, Gasparini et al., (2014) reported the association with QNBC and higher tumor grade. Also, Maeda et al., (2016) showed that TNBC AR+ linked with both low nuclear grade and clinical stage $(\mathrm{p}<0.01)$.

Moreover, in a cohort of 203 Asian patients with TNBC, the Ki-67 index was lower in TNBC AR+ and the incidence of metastasis was high in QNBC (McNamara et al., 2013 and Sutton et al., 2012).

Also, in our results, higher Ki-67 expression, higher grade, and lymph node involvement were statistically significantly correlated with the rate of $\mathrm{pCR}$ in the QNBC group ( $\mathrm{p}=0.02, \mathrm{p}=0.04$, and $\mathrm{p}=0.03$, respectively). This finding matched with the results of many studies evaluated the NAC in TNBC without AR evaluation (Burstein et al., 2008, Keam et al., 2011, and Elnemr et al., 2016). In contrast, no significant association was observed between pCR and clinical-pathological features in the TNBC AR+ group. These findings may reflect the probability of being two different diseases.

Furthermore, we reported that the rate of pCR to NAC was $24.1 \%$ for TNBC AR+ group compared with $60 \%$ of QNBC group. These findings matched with voluminous previous reports (Hilborn et al., 2016; Gerratana et al., 2018; Masuda et al., 2013; Asano et al., 2016; Asano et al., 2017, and ovanović et al., 2017).

Many studies had investigated the predictive value of the AR receptor in BC and in TNBC subtype after NAC. Hilborn et al reported that pCR was $12.8 \%$ and $25.4 \%$ for AR-positive and AR-negative tumors, respectively $(\mathrm{p}<0.0001)$. Among the TNBC group, AR expression predicted a better DFS and OS $\mathrm{p}=0.05$ and $\mathrm{p}=0.03$, respectively) (Hilborn et al., 2016).

Among a retrospective analysis of 130 TNBC patients treated with NAC showed a lower pCR rate for TNBC $\mathrm{AR}+$ subtype $(10 \%)$ in respect to BL1subtype (52\%) (Gerratana et al., 2018; Masuda et al., 2013).

Results of a prospective study by Asano et al included 61 patients with TNBC reported that after NAC, the rate of pCR was statistically significantly lower and more common disease recurrence $(p=0.001, p=0.008$, respectively) in TNBC AR+ compared with QNBC (Asano et al., 2016). After that, the same primary investigator prospectively evaluated the pathological response from 117 TNBC Japanese patients. The results were comparable; the pCR in TNBC AR+ was less frequent than in QNBC. Similarly, Masuda et al through a retrospective study on 146 patients with TNBC, reported lower pCR in TNBC AR+ compared with QNBC (Asano et al., 2017).

In a recent randomized phase II trial to evaluate the NAC (cisplatin, paclitaxel \pm everolimus) in 145 patients with TNBC showed that low expression level of AR was linked to higher pCR than higher AR levels. Moreover, the investigators demonstrated a lack of significant changes in AR levels (before, during or after NAC), suggesting that the chemotherapy did not affect $A R$ expression (Ovanović et al., 2017).

Interestingly, Gong et al., (2014) reported inferior 5-year survival in patients with QNBC compared with TNBC AR+. Three meta-analyses had done by Kim et al., (2015); Wang et al., (2016) and Qu et al., (2013) reported
Neoadjuvant Chemotherapy inTriple Negative Breast Cancer

the significant association with TNBC AR+ and favorable prognosis.

Although most of the previous studies and our results reported the possibility of the use of $A R$ expression as a negative prognostic marker for TNBC, there are few trials had contradicted these results. In a large cohort included 492 patients with TNBC, the authors observed that AR+ was a poor prognostic marker for early-stage TNBC (Choi et al., 2015).

The variations in results may be related to differences in methodology (e.g. different cut off value of AR expression of various studies) or due to variations in patients' characteristics.

Therefore, from the mentioned above and in comparison with QNBC group, TNBC AR+ has a lower $\mathrm{Ki}$-67 expression, lower histological grade, smaller tumor size, more patients are postmenopausal, lower $\mathrm{pCR}$ rate after chemotherapy. Consequently, AR may be a negative predictive marker for the NAC setting. So theses subtype of patients may need more aggressive NAC or combined with an anti-androgen to improve the pathological response and subsequently reflected in survival outcome.

These findings raise the suggestion that TNBCs AR+ patients may represent a subset of patients with unique clinical-pathological features.

Till now, there are no data to support or prevent the routine use of AR assessment even through TNBC. Owing to the availability of anti-androgens such as bicalutamide, many trials had evaluated its use in the metastatic TNBC (Chae et al., 2013; Micello et al., 2010).

Furthermore, preliminary results demonstrated that $A R$ expression may reduce TNBC radiosensitivity. However, there is some data about the use of bicalutamide may restore sensitivity. More evidence is needed to confirm these results.

\section{Limitations}

Retrospective studies are always criticized as the data depend totally on the medical file documentation as well as small sample size represented the primary limitation in our study.

In conclusion, TNBC AR+ is a unique subtype with distinct prognosis and clinical behavior. $\mathrm{AR}$ is a promising predictive marker for TNBC to NAC mainly in our country (developing country) due to the high economic poverty.

\section{Conflict of interest}

The authors certify that there is no potential or actual conflict of interest related to this research.

\section{References}

Anand A, Singh KR, Kumar S, et al (2017). Androgen receptor expression inan Indian breast cancer cohort with relation to molecular subtypes and response to neoadjuvant chemotherapy - a Prospective Clinical Study. Breast Care (Basel), 12, 160-4.

Asano Y, Kashiwagi S, Goto W, et al (2017). Expression and clinical significance of androgen receptor in triple-negative breast cancer. Cancers (Basel), 9, 4.

Asano Y, Kashiwagi S, Onoda N, et al (2016). Clinical verification of sensitivity to preoperative chemotherapy in

Asian Pacific Journal of Cancer Prevention, Vol 21 
cases of androgen receptor expressing positive breast cancer. Br J Cancer, 114, 14-20

Biswas T, Efird JT, Prasad S, et al (2017). The survival benefit of neoadjuvant chemotherapy and pCR among patients with advanced stage triple negative breast cancer. Oncotarget, 8, 112712-9.

Burstein HJ, Harris JR, Morrow M (2008). Malignant tumors of the breast. Cancer: principles and practice of oncology. 8th ed. Philadelphia: Lippincott, Williams and Wilkins, pp 1606-54.

Chae BJ, Lee A, Bae JS, et al (2013). Exression of nuclear receptor DAX-1 and androgen receptor in human breast cancer. J Surg Oncol, 103, 768-72.

Choi JE, Kang SH, Lee SJ, et al (2015). Androgen receptor expression predicts decreased survival in early stage triple-negative breast cancer. Ann Surg Oncol, 22, 82-9.

Collins LC, Cole Ks, Marotti JD, et al (2011). Androgen receptor expression in breast cancer in relation to molecular phenotype: results from the Nurses' Health Study. Mod Pathol, 24, 924-31.

Elnemr GM, El-Rashidy AH, Osman AH, et al (2016). Response of triple negative breast cancer to neoadjuvant chemotherapy: Correlation between Ki-67 Expression and Pathological Response. Asian Pac J Cancer Prev, 17, 807-13.

Gasparini P, Fassan M, Cascione L, et al (2014). Androgen receptor status is a prognostic marker in non-basal triple negative breast cancers and determines novel therapeutic options. PLoS One, 9, e88525.

Gerratana L, Basile D, Buono G, et al (2018). Androgen receptor in triple negative breast cancer: A potential target for the targetless subtype. Cancer Treat Rev, 68, 102-10.

Gong Y, Wei W, Wu Y, et al (2014). Expression of androgen receptor in inflammatory breast cancer and its clinical relevance. Cancer, 120, 1775-9.

Hilborn E, Gacic J, Fornander T, et al (2016). Androgen receptor expression predicts beneficial tamoxifen response in oestrogen receptor-anegative breast cancer. Br J Cancer, 114, 248-55

Ilie SM, Bacinschi XE, Botnariuc I, et al (2018). Potential clinically useful prognostic biomarkers in triple-negative breast cancer: preliminary results of a retrospective analysis. Breast Cancer, 23, 177-94.

Keam B, Im S-A, Lee K-H, et al (2011). Ki-67 can be used for further classification of triple negative breast cancer into two subtypes with different response and prognosis. Breast Cancer Res, 13, 22.

Kim Y, Jae E, Yoon M (2015). Influence of androgen receptor expression on the survival outcomes in breastcancer: a metaanalysis. J Breast Cancer, 18, 134.

Maeda T, Nakanishi Y, Hirotani Y, et al (2016). Immunohistochemical co-expression status of cytokeratin $5 / 6$, androgen receptor, and p53 as prognostic factors of adjuvant chemotherapy for triple negative breast cancer. Med Mol Morphol, 49, 11-21

Masuda H, Baggerly KA, Wang Y, et al (2013). Di-erential response to neoadjuvant chemotherapy among 7 triple-negative breast cancer molecular subtypes. Clin Cancer Res, 19, 5533-40.

McNamara KM, Yoda T, Miki Y, et al (2013). Androgenic pathway in triple negative invasive ductal tumors: its correlation with tumor cell proliferation. Cancer Sci, 104, 639-46.

McNamara KM, Yoda T, Miki Y, et al (2013). Androgenic pathway in triple negative invasive ductal tumors: its correlation with tumor cell proliferation. Cancer Sci, 104, 639-46.

Micello D, Marando A, Sahnane N, et al (2010). Androgen receptor is frequently expressed in HER2-positive, ER/PR-negative breast cancers. Virchows Arch, 457, 467-76.

Mina A, Yoder R, Sharma (2017). Targeting the androgen receptor in triple-negative breast cancer: current perspectives. Onco Targets Ther, 10, 4675-85.

Mougalian SS, Soulos PR, Killelea BK, et al (2015). Use of neoadjuvant chemotherapy for patients with stage I to III breast cancer in the United States. Cancer, 1, 2544-52.

Ovanović B, Mayer IA, Mayer EL, et al (2017). A randomized phase II neoadjuvant study of cisplatin, paclitaxel with or without everolimus in patients with stage II/III triplenegative breast cancer (TNBC): Responses and long-term outcome correlated with increased frequency of DNA damage response gene mutations, TNBC Subtype, AR status, and Ki67. Clin Cancer Res, 23, 4035-45.

Qu Q, Mao Y, Fei X, et al (2013). The impact of androgen receptor expression on breast cancer survival: a retrospective study and meta-analysis. PLoS One, 8, e82650.

Safarpour D, Pakneshan S, Tavassoli FA (2014). Androgen receptor (AR) expression in 400 breast carcinomas: is routine AR assessment justified?. Am J Cancer Res, 4, 353-68.

Sutton LM, Cao D, Sarode V, et al (2012). Decreased androgen receptor expression is associated with distant metastases in patients with androgen receptor-expressing triple-negative breast carcinoma. Am J Clin Pathol, 138, 511-6.

Telli ML, Timms KM, Reid J, et al (2016). Homologous recombination deficiency (HRD) as a predictive biomarkers of response to neoadjuvant platinum-based therapy in patients with triple negative breast cancer. Cancer Res, 76, P3-07-12.

Thike AA, Yong-Zheng Chong L, Cheok PY, et al (2014). Loss of androgen receptor expression predicts early recurrence in triple negative and basal-like breast cancer. Mod Pathol, 27, 352-60

Traina TA, Miller K, Yardley DA, et al (2018). Enzalutamide for the treatment of androgen receptor-expressing triple-negative breast cancer. J Clin Oncol, 20, 884-90.

Wang C, Pan B, Zhu H, et al (2016). Prognostic value of androgen receptor in triple negative breast cancer: a meta-analysis. Oncotarget, 7, 46482-91

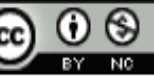

This work is licensed under a Creative Commons AttributionNon Commercial 4.0 International License. 